\title{
Intrasexual fighting and mounting by females of the horned beetle Trypoxylus dichotomus (Coleoptera: Scarabaeidae)
}

\author{
YUTAKA IGUCHI \\ Laboratory of Biology, Yamashita-cho 1-10-6, Okaya City, Nagano Prefecture, 394-0005, Japan; e-mail: bio-igu@f8.dion.ne.jp
}

Key words. Scarabaeidae, Trypoxylus dichotomus septentrionalis, horned beetle, female intrasexual fighting, female intrasexual mounting, alternative tactic

\begin{abstract}
Although females of the horned beetle, Trypoxylus dichotomus septentrionalis, have only small horns they often fight over access to feeding sites by head-butting each other. In addition, they sometimes show intrasexual mounting. In this study 82 females of different sizes were used to determine the relationship between fighting and mounting. Large females more often won fights and so gained access to food than small females. In contrast, small females more often mounted large females and then gained access to food than large females. These results suggest that female mounting may function as a tactic for reducing intrasexual fighting between small and large females.
\end{abstract}

\section{INTRODUCTION}

Fighting for possession of feeding sites is a characteristic feature of male horned beetles. Large males have large horns, fight more intensely and have an advantage over small males in fights for possession of feeding sites (Eberhard, 1980; Otronen, 1988; Rasmussen, 1994; Emlen, 1997; Moczek \& Emlen, 2000). This behaviour is particularly well studied in the horned beetle Trypoxylus dichotomus septentrionalis (Kono, 1932) (= former Allomyrina dichotoma septentrionalis) (Siva-Jothy, 1987; Iguchi, 2001; Hongo, 2003, 2007; Karino \& Niiyama, 2006).

Although there are many studies on the fighting behaviour of male horned beetles there are very few on female fighting. In $T$. $d$. septentrionalis the females have only small horns, but often fight by head-butting each other when competing for a feeding site (Fig. 1; Iguchi, 1996; Hongo, 2003; also see a film made by Iguchi, 2007). Hongo (2003) reports that large females win fights with small females, but this was based on only 9 observations. Therefore, the effect of female body size on the outcome of fights between females is not yet fully understood.

Interestingly, female $T$. $d$. septentrionalis show intrasexual mounting as well as fighting at feeding sites (Fig. 2; Iguchi, 1996; Tanaka, 1999; Abe et al., 2006). Female mounting is reported in insects (Harari et al., 2000). Harari \& Brockmann (1999) show that female intrasexual mounting in the sexually monomorphic weevil Diaprepes abbreviatus attracts males, but Abe et al. (2006) suggest that in $T$. $d$. septentrionalis it does not. Therefore, the function of female intrasexual mounting in $T$. d. septentrionalis is unknown.

In this study, the behaviour of female $T$. d. septentrionalis at feeding sites was observed and the following four questions addressed: (1) are large females more likely to win fights than small females? (2) do the mounting and mounted females differ in body size? (3) do small and large females differ in the frequency of mounting before and after fighting? and (4) do small and large females differ in the probability of gaining access to food after fighting and mounting? The objective is to understand the significance of intrasexual fighting and mounting in female $T$. d. septentrionalis.

\section{MATERIAL AND METHODS}

A total of 82 adult females of $T$. d. septentrionalis were collected in 2008 in Hokuto City, Yamanashi Prefecture, Japan. These females were separated into two groups consisting of 41 large and 41 small females, and then the large females were paired at random with small females. These 41 pairs of small and large females were used in this study. The body length of each female was measured from the front of the head to the tip of the elytra. In addition, in order to discriminate easily between the large and small female in each pair each female was marked on the elytra with a small dot of white enamel paint. Preliminary observations indicated that females fight and mount other females regardless of whether they are marked with paint or not. Moreover, there is no report that such marks influence fighting or mounting in this beetle and this means of distinguishing the beetles has been used in several studies on this beetle (SivaJothy, 1987; Hongo, 2003, 2007).

Prior to an experiment, transparent plastic containers $(15 \mathrm{~cm}$ long $\times 10 \mathrm{~cm}$ wide $\times 11 \mathrm{~cm}$ deep) were filled to a depth of $3 \mathrm{~cm}$ with moist humus. An oak block $(13 \mathrm{~cm}$ long $\times 7 \mathrm{~cm}$ wide $\times 3$ $\mathrm{cm}$ high), with a hollow in the upper surface filled with a mixture of brown sugar and water, which acted as an artificial feeding site, was placed in each container. Prior to the experiment, females were kept individually in plastic boxes.

The experiment was carried out in Laboratory of Biology, Okaya City, Nagano Prefecture, Japan in August 2008. A pair of females was put in each container, with the large female placed on the surface of the humus on one side of the oak block and the small female on the other side. Feeding sites were filled with the brown-sugar water mixture at 19:00 and 1:00. Observations were carried out under dim red light at room temperature $\left(24-30^{\circ} \mathrm{C}\right)$ continuously from 19:30 to $4: 30$ when either or both females were on the oak block or the humus surface or moving and at intervals of 15-30 min when both females remained 


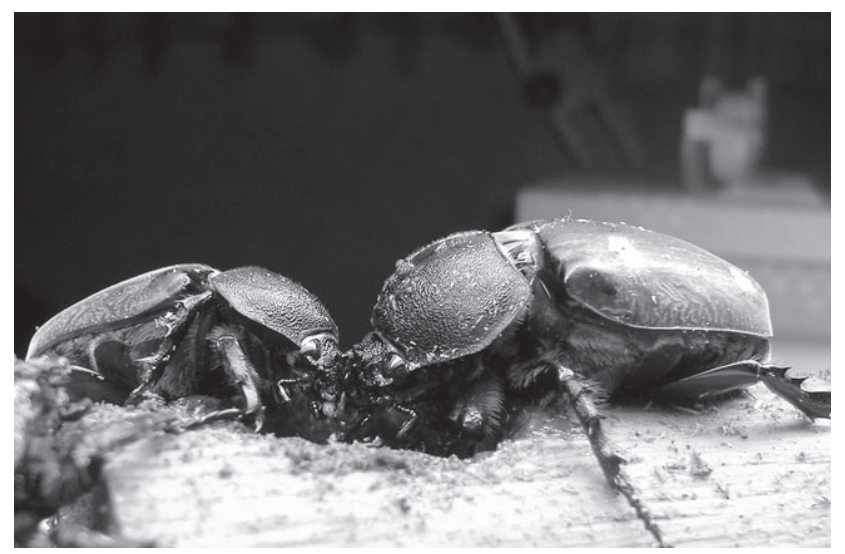

Fig. 1. Female intrasexual fighting. This photograph shows two females head-butting for the possession of a feeding site.

motionless under the oak block or the humus. This procedure was repeated for each pair of females until both fighting and mounting were observed or for a maximum of 10 days.

The behaviour of the beetles in the 41 pairs of small and large females was recorded as follows:

(1) When two females fought each other by head-butting for possession of a feeding site the female that pushed or threw the other female away from the feeding site, monopolized the food and then started feeding was classified as the winner and the other as the loser.

(2) When one female mounted the other at the feeding site, whether it was the small or large individual was recorded.

(3) Whether each female mounted her partner before or after fighting was also recorded.

(4) Whether a female gained possession of the food after mounting was recorded and the probability of gaining food after fighting compared with that after mounting.

\section{RESULTS}

Fighting was observed in 38 pairs and mounting in 32 pairs.

Mounting ended in one of three ways: (1) a fight between the mounting and mounted females occurred (4 out of 32 mountings); (2) the mounted female ran away from the mounting female (4 out of 32 mountings); and (3) the mounted female remained motionless and con-

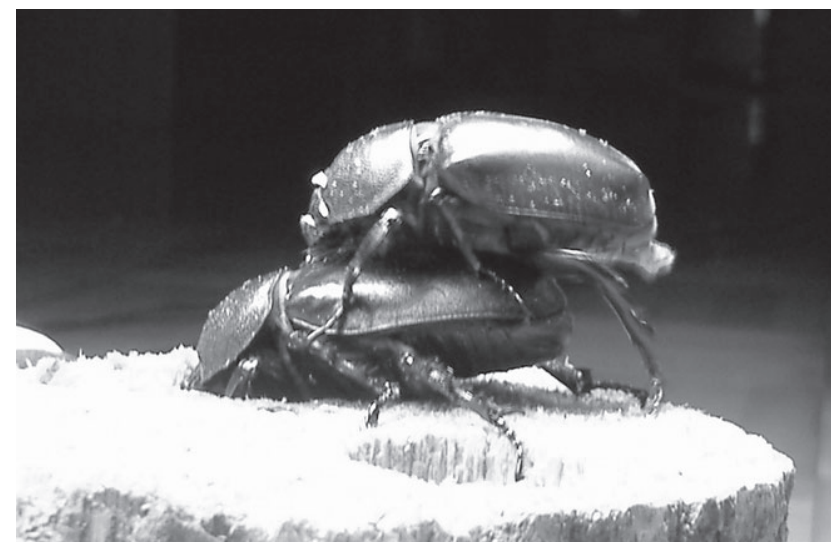

Fig. 2. Female intrasexual mounting. In this photograph the mounting female is extending her ovipositor towards the mounted female's genital organ.

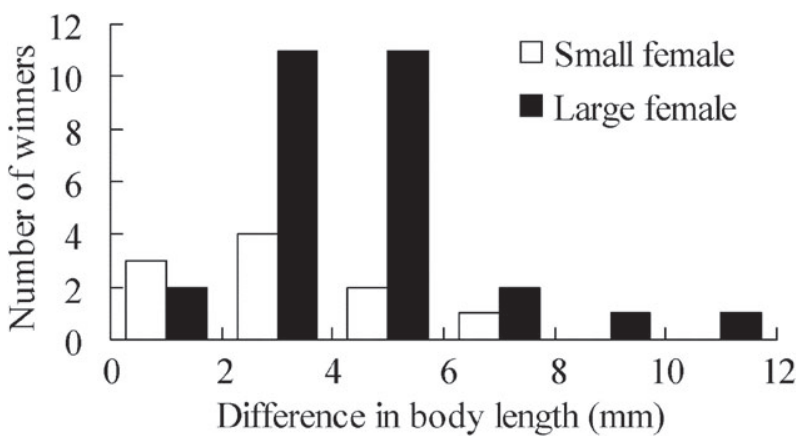

Fig. 3. The effect of female body size on the outcome of intrasexual fighting. The data were obtained from 38 fights between small and large females. The frequency distributions show the number of small females that won fights against large females (white bars) and vice versa (black bars). The differences in the lengths of the bodies of the small and large females are shown on the horizontal axis as: $0-2,2-4,4-6,6-8,8-10$ and $10-12 \mathrm{~mm}$. As the difference between the lengths of the bodies of the females increased there was an increase in the proportion of large females winning fights against small females.

tinued to feed, and the mounting female dismounted (24 out of 32 mountings). That is, fighting was only recorded in 4 out of 32 mountings. This indicates that in this situation fighting between females rarely occurred (4/32, binomial test, $\mathrm{p}<0.0001$ ).

As shown in Fig. 3, large females more often won fights than small females (Wilcoxon signed-ranks test: $\mathrm{z}$ $=3.50, p=0.0005)$. As the difference in the body size of the females increased, the proportion of wins by large females increased (Spearman rank correlation, $r_{s}=0.88, p$ $=0.008$ ).

As shown in Fig. 4, small females more often mounted large females than vice versa (Wilcoxon signed-ranks test: $\mathrm{z}=2.17, \mathrm{p}=0.03$ ). As the difference in the body size of the females increased, the proportion of mounting by

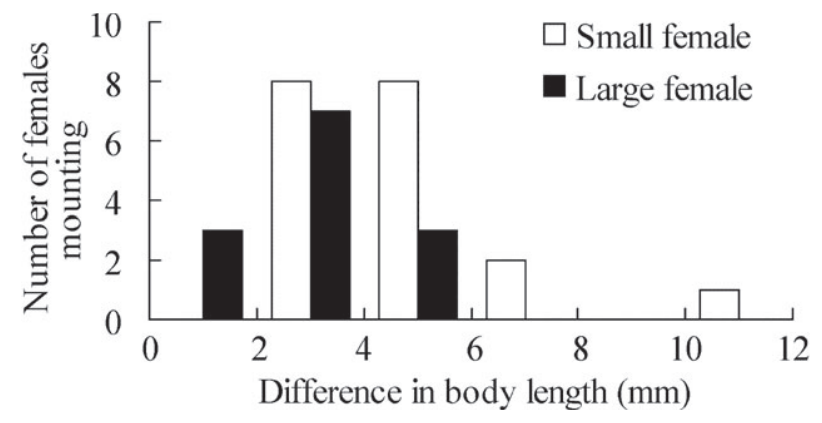

Fig. 4. The effect of female body size on intrasexual mounting. The data were obtained from 32 mountings between small and large females. The frequency distributions show the number of small females mounting large females (white bars) and vice versa (black bars). The differences in the lengths of the bodies of the small and large females are shown on the horizontal axis as: $0-2,2-4,4-6,6-8,8-10$ and $10-12 \mathrm{~mm}$. As the difference between the lengths of the bodies of the females increased there was an increase in the proportion of small females mounting large females. 


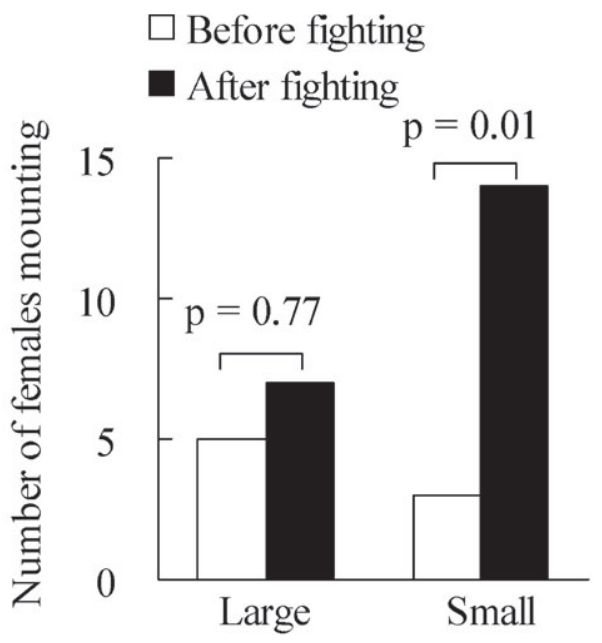

Fig. 5. The effect of female intrasexual fighting on mounting. The data were obtained from 29 mountings that occurred before or after fighting. Small females mounted large females more frequently after than before fighting (right white and black bars), whereas large females mounted small females almost as frequently before as after fighting (left white and black bars). The results of the binomial tests are given above the columns.

small females increased (Spearman rank correlation, $\mathrm{r}_{\mathrm{s}}=$ $0.98, \mathrm{p}=0.005$ ).

As shown in Fig. 5, small females mounted large females significantly more often after than before fighting, whereas large females mounted small females almost as often before as after fighting.

As shown in Fig. 6, small females mounted large females significantly more often after losing than after winning fights, whereas large females mounted small females almost as often after winning as after losing fights.

The probability of small females gaining access to the food after mounting is almost equal to that recorded for those that won the fight (mounting, $4 / 19=21 \%$; winning, $10 / 38=26 \%$; Fisher's exact test, $p=0.75$ ). The probability of large females gaining access to the food after mounting is lower than after wining a fight, although not significantly so (mounting, $6 / 13=46 \%$; wining, $28 / 38=$ $74 \%$; Fisher's exact test, $\mathrm{p}=0.09$ ).

\section{DISCUSSION}

Otronen (1988) suggested that fighting between female horned beetles is closely associated with whether the females have horns. However, the present study showed that although female $T$. $d$. septentrionalis have only small horns, they often fight each other for access to feeding sites (also see a film recorded by Iguchi, 2007). Previous studies on this species show that large males win fights with small males (Siva-Jothy, 1987; Iguchi, 2001; Hongo, 2003; Karino \& Niiyama, 2006). The results of the present study reveal that females also fight and that large individuals were more likely to win fights over access to food than small individuals. This suggests that large females have an advantage in intrasexual fighting.

Interestingly, small females that mounted large females after losing a fight were as successful at gaining access to

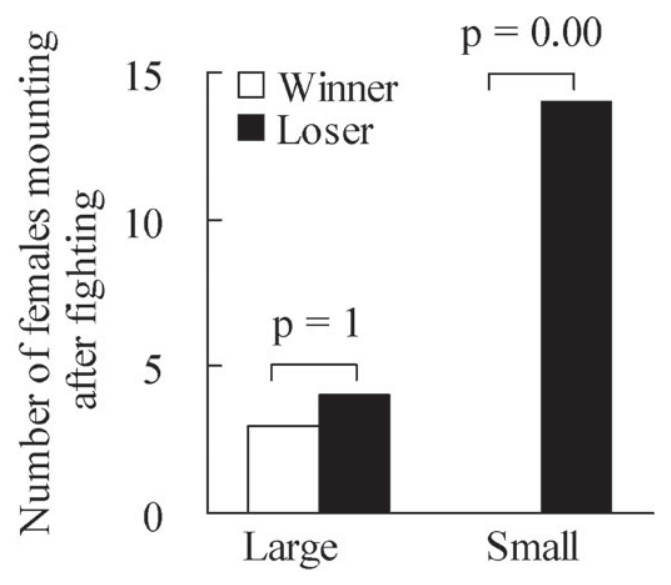

Fig. 6. The incidence of mounting during female intrasexual fighting. The data were obtained from 21 female mountings that occurred after fighting. In all cases small females mounted large females after losing fights (right black bar), whereas large females mounted small females almost as frequently after winning as after losing fights (left white and black bars). The results of the binomial tests are given above the columns.

food as those that won fights. It is noteworthy that fights between the mounting and mounted females were rarely observed. This indicates that mounting by females may be an alternative tactic to fighting. This is the first time this has been proposed as an explanation for the relationship between mounting and fighting in female beetles, but similar explanations have been offered for other animal taxa, such as primates (Vasey, 1995; Hohmann \& Fruth, 2000).

Many studies on male horned beetles have shown that small, competitively inferior males adopt a nonaggressive tactic when interacting with large males (Emlen, 1997; Moczek \& Emlen, 2000; Hongo, 2003; Karino \& Niiyama, 2006). Therefore, it is not strange that small, competitively inferior females similarly adopt a non-aggressive alternative tactic.

In the weevil $D$. abbreviatus, female intrasexual mounting attracts large males, and therefore this behaviour is likely to increase reproductive success (Harari \& Brockmann, 1999; Harari et al., 2000). For horned beetles, including $T$. $d$. septentrionalis, there is no data on whether mounting increases a female's reproductive success. Abe et al. (2006) and personal observations suggest that at least while mounting, females are unlikely to mate with males. However, after mounting, females may mate with males. Further studies are required on the reproductive benefit of mounting for females.

\section{REFERENCES}

Abe H., Fujita T., Suzuki A., Sato T., Iwabuchi K. \& Obara Y. 2006: Elicitation of male mating behavior in females in insects: The cases of Japanese horned beetle, a long-horned beetle, a silk worm and other. Jpn. J. Sexuol. 24: 7-16 [in Japanese with English abstr.].

Eberhard W.G. 1980: Horned beetles. Sci. Am. 242: 124-131.

EMLEN D.J. 1997: Alternative reproductive tactics and maledimorphism in the horned beetle Onthophagus acuminatus 
(Coleoptera: Scarabaeidae). Behav. Ecol. Sociobiol. 41: $335-34$.

Harari A.R. \& Brockmann H.J. 1999: Male beetles attracted by females mounting. Nature 401: 762-763.

Harari A.R., Brockmann H.J. \& Landolt P.J. 2000: Intrasexual mounting in the beetle Diaprepes abbreviatus (L.). Proc. $R$. Soc. Lond. (B) 267: 2071-2079.

Hohmann G. \& Fruth B. 2000: Use and function of genital contacts among female bonobos. Anim. Behav. 60: 107-120.

Hongo Y. 2003: Appraising behaviour during male-male interaction in the Japanese horned beetle Trypoxylus dichotomus septentrionalis (Kono). Behaviour 140: 501-517.

Hongo Y. 2007: Evolution of male dimorphic allometry in a population of the Japanese horned beetle Trypoxylus dichotomus septentrionalis. Behav. Ecol. Sociobiol. 62: 245-253.

IGUCHI Y. 1996: Sexual behavior of the horned beetle, Allomyrina dichotoma septentrionalis (Coleoptera, Scarabaeidae). Jpn. J. Entomol. 64: 870-875.

IGUCHI Y. 2001: Differences in the frequency of fights between minor and major males in the horned beetle Trypoxylus dichotomus septentrionalis (Coleoptera: Scarabaeidae). Entomol. Rev. Jap. 56: 11-14.

Iguchi Y. 2007: Female-female fighting behavior of the Japanese horned beetle. Movie Archives of Animal Behavior, Data
No. momo071108td01b (http://www.momo-p.com/showdetail -e.php?movieid=momo071108td01b)

Karino K. \& Niryama H. 2006: Males with short horns spent more time mating in the Japanese horned beetle Allomyrina dichotoma. Acta Ethol. 9: 95-98.

Moczek A.P. \& Emlen D.J. 2000: Male horn dimorphism in the scarab beetle, Onthophagus taurus: do alternative reproductive tactics favor alternative phenotypes? Anim. Behav. 59: 459-466.

Otronen M. 1988: Intra- and intersexual interactions at breeding burrows in the horned beetle, Coprophanaeus ensifer. Anim. Behav. 36: 741-748.

RASMUSSEN J.L. 1994: The influence of horn and body size on the reproductive behavior of the horned rainbow scarab beetle Phanaeus difformis (Coleoptera: Scarabaeidae). J. Insect Behav. 7: 67-82.

SivA-Jотну M.T. 1987: Mate securing tactics and the cost of fighting in the Japanese horned beetle, Allomyrina dichotoma L. (Scarabaeidae). J. Ethol. 5: 165-172.

TANAKA Y. 1999: Pseudocopulation behavior in female Allomyrina dichotoma septentrionalis. Gekkan-mushi 346: 37-38 [in Japanese].

VASEY P.L. 1995: Homosexual behavior in primates: A review of evidence and theory. Int. J. Primatol. 16: 173-204.

Received July 2, 2009; revised and accepted November 18, 2009 